\title{
Care of the Self and Subjectivity in Precarious Neoliberal Societies
}

\author{
Brunella Casalini* \\ Department of Social and Political Science, University of Florence, Italy
}

\begin{abstract}
This paper aims at analyzing precarity as an existential condition that is structural and that permeates one's affective environment. The uncaring rules of contemporary public management and their competitive spirit produce a sense of widespread precarity. This paper explores the effects of this sense of precarity on subjectivities, specifically in relation to those operating in domains with a caring mission, such as social work or university education and research, where burnout, depression and exhaustion, due to trying to comply with new rules, often occurs. However, it is also possible to find other reactions, such as cynicism, which, when directed not towards those who expect care but towards the organization itself, may be a form of resistance that signals an alternative approach to care of the self in the face of systemic neoliberal imperatives. These alternative tendencies in relation to care of the self suggest not only the relevance, from a care ethics perspective, of referring to Michel Foucault's interpretation of neoliberalism, but also of his reflections on the link between the classical tradition of care of the self and care of others. Given the deleterious effects of neoliberalism on care of the self and of others, care ethicists in particular need to be aware of options emerging to express care of the self and of others more appropriately.
\end{abstract}

Keywords

Precarity, Care ethics, Care of the self, Care for others, Academy, Social work

\section{Introduction}

The word "precarity" derives from the Latin prex and precis, meaning request or prayer. The Latin precarius, used both as a religious and juridical term, meant "obtained by prayer", as a favor, in an asymmetrical relationship of dependency, and thus was always revocable, with no guarantee of lasting over time. Through an extension of its original meaning, "precarious" has come to mean something that is uncertain or insecure [1]. Since the end of the 1980s, the term precarity has been used to describe the new social insecurity experienced by many in "precarious work", meaning work that is "uncertain, unstable, and insecure, and in which employees bear the risks of work (as opposed to business or the government) and receive limited social benefits and statutory entitlements" [2]. A political debate on precarity has gained ground in anti-globalization and anti-neoliberal social movements in the new millennium. In 2001, the so-called EuroMayDay movement, clearly echoing Marx's "proletariat", began using the term precariat to describe groups of individuals who find themselves in a state of precarity. Precarity has thus emerged as a polemical word used by social movements to contrast and critique the rise of rhetoric in which flexibility has been promoted as a freedom enjoyed by both corporations and the individuals who work for them [3].
This paper does not discuss the opportuneness of considering those who are affected by precarity as a class [4], nor does it offer a political or economic analysis of the phenomenon. Precarity is considered here as a condition, involving not only work but more generally the condition of living with insecurity, uncertainty and possible exploitation as well as social suffering that affects most of the population. Precarity may also be considered as "a regime, a hegemonic mode of being governed and governing ourselves" [5]. It is not only an economic condition, but "it is structural in many senses and permeates the affective environment too" [3].

This paper first explores how this regime of precarity legitimizes itself and what the discourses are that explain its present dominance in our societies and, second, the consequences of the resulting uncertain and insecure social landscape on care of the self and care of others, in particular within those professions with a clear vocation towards care

*Corresponding author: Brunella Casalini, PhD, Political Philosophy, Associate Professor, Department of Social and Political Science, University of Florence, Italy

Accepted: February 07, 2019

Published online: February 09, 2019

Citation: Casalini B (2019) Care of the Self and Subjectivity in Precarious Neoliberal Societies. Insights Anthropol 3(1):134-139 
of others.

In line with Michel Foucault's analysis of neoliberalism [6], I consider that neoliberalism operates not through guaranteeing security but through deliberately fostering insecurity to produce individuals who must demonstrate risk-taking ability [7]. Neoliberal individuals cannot be described simply as sovereign, unrelated and egoistical, acting on the basis of a prudential and calculating rationality; instead neoliberalism works to explicitly undermine care ethics [8-10] precisely because it sets out to profit from affective relationships, the provision of care, and the very real vulnerability and dependency experienced by so many individuals. As Puig de la Bellacasa states: "Calls for care are everywhere, from marketing of green products, by which companies compete to show how much they care, to the purchase of recycled items, by which consumers show that we care" and "neoliberal governance has made of caring for the self a pervasive order of individualized biopolitical morality" [10]. The neoliberal world is one that produces insecurity and, at the same time, calls on every individual to take care of his or her vulnerability and precarity and to achieve resilience, that is, a capacity to endure periodic, inevitable moments of crisis while remaining ever capable of springing back after each setback.

What I contend, therefore, is that neoliberalism requires a "self-care" [11] that, while not inevitably excluding care of others, necessitates an instrumental approach to care, which renders genuine self-care and care of others virtually impossible, at least for most persons.

Some contemporary literature on academic and social work conditions helps illustrate how the reality of uncaring rules within countries heavily influenced by neoliberalism produce societies characterized with burnout [12], fatigue, isolation and depression, in which care is as desperately needed as it appears to be impracticable. As care ethics reveals [8], real care for oneself and others needs time, a sense of limits, an orientation not towards future achievements but towards the present, a recognition of the importance of ordinary everyday life, attention to the concrete other and the specific context in which one has to operate, and a capacity to slow down, listen and think. These care values clash with the logic of new public management, and it is this clash that lies at the core of the present organizational malaise in academia as well as in social work and in other care-oriented professions. However, it is noteworthy that, along with a sense of precariousness, fatigue, exhaustion and depression $[13,14]$ the response in some cases has also involved widespread cynicism among professionals (whether social workers or academics and researchers) towards institutions and present assessment policies, which could be interpreted both as a form of care of the self and as a form of resistance [15-18]. This suggests that care ethics, in responding to the neoliberal appropriation of the concept of "care", needs to develop a more complete picture of what care of the self entails in its relationship with care of others. In this direction, Foucault's attempt later in his career to work on care of the self and the practice of critique as a practice of freedom needs to be revalued and taken more seriously than hitherto by care ethicists [19].

\section{Regulating through Insecurity}

According to Foucault, neoliberalism should be considered as a particular governmental practice or art to regulate the conduct of individuals, which induces them to do what is expected, involving a specific "rationality of government" or "art of governing" or "governmentality" $[6,20]$. This peculiar "rationality of government" is a recent phenomenon and does not aim at controlling a territory but rather at governing a population. It is thus linked to biopolitics, which, according to Foucault, has two distinct aspects involving either anatomo-politics that characterizes disciplinary institutions and a disciplinary society or biopower that acts on the population as a whole through the application of security technologies $[6,20]$. With the shift from liberalism to neoliberalism, disciplinary institutions have not disappeared but have become less important. There has been a shift from a disciplined society to a "control society" or, better, according to Byung-Chul Han [12], to an "achievement society" (Leistung Gesellschaft).

If according to nineteenth-century liberalism, the State had to limit itself through allowing space for the selfregulatory mechanisms of market exchange, in contemporary neoliberalism the market legitimizes the very existence of the State [6]. The neoliberal State must govern in an active way to create a specific juridical framework and the conditions for what is perceived as facilitating the correct functioning of market competition, including privatizing social risk costs, that is, privatizing social security. The most effective way to achieve this latter goal is to produce individuals or subjectivities able to adapt to a competitive market environment in which there are no longer horizontal relationships of exchange, but only competition involving winners and losers.

The actor in a neoliberal market society is no longer engaged simply in market exchange (as in Adam Smith's theory), but becomes instead what Foucault calls an "entrepreneurial self", a term coined by the Chicago School of Economics. According to this economic vision, each person has human capital which he or she only has to invest [6]. This human capital can be constituted by whatever an individual has in terms of personal qualities, including knowledge, affective and emotional capacities, creative faculties, sexual appeal, beauty and other relevant features. Everybody can derive a profit from his or her human capital, since it is just a matter of continuously investing in oneself and never ceasing to improve oneself in order to win the race for success, with everyone called on to participate.

This vision has had many far-reaching consequences on the lives of neoliberal individuals. The first, as is clear from the work of Chicago School economist Gary Becker, involves an extension of the field in which economic analysis is considered relevant, with few areas remaining immune from and untouched by work time and economic reasoning. It is no accident that Becker included the family, and decisions on whether to have children, how many, which school to send them to, and so on, within the sphere of economic behavior, which had otherwise been considered outside the rationalizing calculus of the economic actor [21]. In explaining the human capital theory of the Chicago School of Economics, 
Foucault uses the example of a mother in relation to the entrepreneurial self to show how important the mother's role can be in increasing the value of the economic capital of her child, in terms of the quality of affection she gives to the child, whether she is able to breastfeed the child, and so on. This example is important, first, because it shows the nature of the relationship between a neoliberal individual and another person. Here, it is not a question of an egoistic and unrelated individual, but rather of an individual, a mother, who can even sacrifice herself if it helps to invest in her child's human capital. The neoliberal individual is not in control of his or her life, since he or she must follow the laws of competition. To invest in oneself is not really an option but a systemic necessity, and failure to do so will inevitably result in an individual being cast out of society and finding himself or herself at its margins as a loser. The mother example is important, second, because it shows that all those individuals called on to do care work for others (mainly comprising women) need to apply a different attitude to their work. Care fundamentally now concerns improving and perfecting the care receiver, and such improvement must be susceptible to some form of measurement and achievement assessment. "Self-care" and care of others are not absent, but now need to be conceived as an investment and legitimized as an investment, that is, pursued in terms of profit or as a means to add value to one's human capital.

Another consequence of the neoliberal vision of the individual is that he or she operates in an 'economy of promise', in which the future seems to be the only temporal dimension that receives full attention. This means that one is called on to invest in oneself, or to invest in those one cares for, in view of some possible reward or achievement not attainable now but which can be expected in the future. This expectation of future rewards generates a "cruel optimism": as Lauren Berlant explains, "optimism is cruel when the object/scene that ignites a sense of possibility actually makes it impossible to attain the expansive transformation for which a person or a people risks striving" [3].

\section{The Hidden Injures of the Neoliberal Individ- ual}

Foucault's interpretation of neoliberalism, and the contemporary revival of his interpretation, helps understand not only the peculiar role of the State both in creating an unregulated and flexible labor market and in privatizing social security and social reproduction (involving, for example, families obliged to mortgage their homes or otherwise take on debt to pay for social assistance or health care, or when young people must accept unpaid internships to have the chance of finding a job, as happens more often in a world of reduced welfare states and uncertain labor markets), but also, and importantly for this article, the psycho-social effects of neoliberalism on everyday life in terms of its role in producing a particular kind of subjectivity. In particular, Foucault's analysis in his 1977-1978 Lectures on Biopolitics helps elucidate the collusion between certain forms of contemporary subjectivities and the new spirit of neoliberal capitalism. Neoliberalism aims at forcing individuals to enter the economic arena through a new individualizing social politics that makes it possible to avoid the bureaucratic norms of the old welfare state. All that each person is now required to offer is the value of his or her human capital. There is no need to expect from an individual any behavioral or ideological conformity, only that he or she competes in the economic arena. There is no need for normalization, insofar as each individual shares the internal logic of valorization concerning one's own human capital. Rather than submitting to norms that one must interiorize or laws that one must fear, what is required instead is rational and orderly conduct [22]. The neoliberal individual is extremely easy to govern; all that is needed is to change the environment. Consider, for example, the effects of the new assessment processes introduced into the neoliberal Academy concerning the behavior of researchers, for example, regarding the so-called "impact factor". The behavioral changes occurring among contemporary academic researchers result from simple adaptation to new rules necessary to survive in the system. The neoliberal individual is invited to think of himself or herself as free, but in fact is dependent on the imperatives of the neoliberal social environment, which is presented as unavoidable if economic growth is to be fostered. In this environment, as Michel Feher [23] underlines, the individual must guard against the loss of market value for his or her human capital, and this entails a relentless drive towards selfassessment and investment in oneself.

It follows from this analysis that the neoliberal individual is rendered precarious or, more accurately, feels precarious no matter what his or her working conditions are, because of a dependency on a capacity to adjust, adapt to and follow the logic of the system with its competitive rules. As competition under the myth of so-called "meritocracy" becomes more acceptable and harsh, inequalities grow. In many Western countries today, an unprecedented level of inequality has been reached (the richest $1 \%$ owns half of the world's wealth), in which wealth is derived mainly from speculative financial investment in a sort of rent capitalism that harks back to aspects of medieval feudalism.

Thus, it is not accidental that almost the same symptoms of social suffering can be found both among those who have a more stable working situation and among those who are out of work or in an uncertain work situation, namely, depression, anxiety, and exhaustion, as well as a sense of solitude and, even more, of isolation. Depression, anxiety and a sense of isolation are caused by the continuous push to compete, which does not spare those who have a steady job, since they not only have to keep up with the rules of continuous assessment of the new public management philosophy that increasingly permeate both private enterprise and public institutions, but also cannot avoid feeling privileged, whatever their conditions, in comparison to those who have a less secure work status and thus cannot afford the luxury of complaining or refusing to follow the logic of the system. For many outside the market, the effect of rejecting competition can reach the point of preferring complete isolation, as in the well-known social phenomenon of hikikomoro, involving very young people who decide to leave school, refuse any kind of social contact and choose to retreat into the security of their bedrooms. 
Exhaustion, burnout and fatigue are more often the result of a continuous push to speed up one's lifestyle, hyperactivity and the disappearance of boundaries between living and working, indicating a discrepancy between the rhythms, speed and demands of the neoliberal environment and the physical capabilities of humans. Theresa Brennan coined the term "bioderegulation" to describe this gap [24]. Working longer hours and reducing our sleep hours has become mandatory. It is not unusual to read in the biographies of famous entrepreneurs, managers or successful people more generally that they sleep fewer than six hours a day. This implicitly suggests that one has to rationalize one's conduct in a certain way if one wants to succeed, even if medical research indicates that, although sleep requirements may vary among individuals, in general healthy adults need to have at least seven to eight hours sleep per night to function properly. As Jonathan Crary claims: "The decline in the longterm value of living labor provides no incentive for rest or health to be economic priorities, as recent debates around healthcare have shown. There are now very few significant interludes of human existence (with the colossal exception of sleep) that have not been penetrated and taken over as work time, consumption time, or marketing time" [24]. No matter how much one is pushed to care for oneself, the neoliberal urge to invest in oneself through consumption does not respond to humans needs and does not take human capabilities seriously. Neoliberal "self-care" is not based on ethics, nor inspired by moral values, but involves demands validated by science (be it from medicine or psychology or even sexology) or economics, and expects the individual to follow variously the dictums of medicine or psychology, or those of the market. It is a strategy for coping with presentday precarity, as indicated by the flourishing contemporary self-help literature on this subject $[25,26]$.

\section{Care of the Self, Caring for Others and the Role of Cynicism in Neoliberal Caring Institutions}

As shown in care ethics, good care for the other cannot occur when good care of the self is lacking. Insofar as precariousness, insecurity and competition lead to isolation and depression, they can threaten social bonds and drain capacities for social solidarity. In the rush to win the race, which often simply means the rush to survive, it is difficult to stop and help those who have fallen. However, it is worth considering what happens in such a scenario, as much empirical research literature has recently done, for those professions in which the provision of care is an unescapable professional duty, such as social work or academic teaching and where a gender component plays an important role. The academic world has become increasingly burdened with socalled organizational housework, which includes not only the didactic side of academic work, dealing more directly with students (teaching, examining, thesis supervising, $\mathrm{PhD}$ research, and so on) but also the growing load of administrative and managerial tasks that professors have in the neoliberal university due to the processes of quantitative periodic assessments of their work.

All caring professions are under pressure, and it is not surprising to find similar stories not only of "cruel optimism", burnout, depression, self-exploitation, and a desire to give up and leave the job, but also of differing negative attitudes such as cynicism, associated with emotions that range from shame to rage. There is often shame in confessing one's inability to keep up with the pace set by an organization and to overcome the contradictions between professional values and organizational imperatives, and a tendency for individualized anxieties and worries to develop in attributing such inability to personal bad choices or in pressure to further enhance oneself, one's human capital and act accordingly. There is also in many cases a rising cynicism that may kindle rage and contempt.

Neoliberal culture itself, in its blending with rightwing populism, can be considered as feeding a widespread social cynicism, as with Donald Trump's or Matteo Salvini's rhetoric concerning women and immigrants. When synonymous with social insensibility and indifference, social cynicism may have dangerously corrosive effects on social bonds. Cynicism, however, does not always have a negative meaning. For the ancient Cynic philosophers, such as Diogenes the Cynic, cynicism was an extreme form of self-defense or care of the self that one had to bring into play whenever there was a risk of being overwhelmed by social meaninglessness.

Cynicism can be detrimental to the quality of care when it is directed towards those who are the receivers of care, as sometimes can happen, especially when there is too much job pressure. In some care work professions, such as child-care and care for the elderly, many recent episodes of violence can be linked at least in some measure to bad working conditions that create excessive stress on the care worker. Cynicism, however, is often also a form of resistance or dissidence towards institutions and organizations that have adopted new public management approaches under neoliberalism and whose internal bureaucratic and formalistic rules clash with the substantial ethical values that orient professional caring practices $[17,18]$. In this sense, cynicism may be seen as a type of shield that protects one from excessive work demands or from malaise produced by the clash between deontological values deeply rooted in the practice of caring work, and abstract and most often merely quantitative organizational objectives and assessment criteria. Cynicism could be seen as a way to cope with and survive stressful work settings and the conflicts that may arise in the different phases of care [8].

Cynics "may act as the voice of conscience for the organization, much as the Cynics did for their culture" [27]. Cynicism could thus be the first manifestation of a critique of neoliberal governance. In particular, in the caring professions, the care required for others leads the care-providing individual towards (and at the same time requires) a care of the self that is capable of resisting the power of organizational routines and of criticizing principles that are imposed from above on the care relationship itself. In these cases, the cynicism of the social worker or of the academic teacher $[17,18]$, as two examples from professions otherwise very different, seems to embody the spirit of the classical Cynic way of life in which "the Cynic care of the self involves care for others as well" [28]. 
According to [17], in the case of care workers: "From cynicism felt towards policy makers or wider organizational agendas there also emerge acts of rule bending or other forms of deviance. Such acts included exaggerating service user or care needs on official forms (to increase possible support) or in supervision, ignoring procedure or policy such as by fulfilling a now seemingly defunct service 'provider' role (e.g. by offering counseling or advocacy or direct physical support to users) or on occasion at least, encouraging service users to claim benefits or access support services that they were not officially entitled to".

Academic work also presents a similar orientation towards a care of the self that is, at the same time, a care for others, with the critique of the slow academy movement, which has turned feelings of shame and depression into a greater skeptical willingness to critique the rules of the neoliberal academic system [29]. The slow science movement has become a form of resistance to neoliberal reforms that started both from a willingness to heed the general sense of malaise present in the contemporary neoliberal academy, even in those who hold tenure track faculty positions, and from a widespread cynicism about the transformations introduced by the new public management in universities. This resistance involves a capacity to distance oneself from the idea that those public management rules are necessary and inevitable, and that depression is due to a personal incapacity to deal with them. It is possible to conclude that, in the slow science movement, depression, shame, and bad feelings have been reconfigured as public feelings widely shared in the neoliberal Academy, and no longer comprehensible as personal medical problems, which has turned medicalized "self-care" into a political care of the self [30].

As these cases show, it is through people paying greater attention to what is happening to themselves in contextual terms (which for Foucault meant our bodies as well as our minds) and to others in interactions within the constrictions and rules that are presented by the system as necessary and unavoidable, that it is possible to develop a consciousness of personal feelings as public feelings and thus as a possible source of critique. This critique does not aim at an abstract freedom, but at a practice of freedom that starts from the recognition of the arbitrary and contingent nature of any existing social order.

\section{Conclusion}

The neoliberal concept of "self-care" is a form of selfmanagement that follows the rules of the economic system, or of medicine or psychology. It is thus a type of servitude or enslavement generated as a top-down external normativity presented as a scientific truth, with the individual constituted through an external nomos. As Murray [11] states concerning neoliberalism, "the care of self-care is based on utility, it is a utilitarian ethic, a medicalized self-relation that is not freely defined by the self, but that is promoted and constrained by the norms of the medical, insurance, and pharmaceutical industries, by HMOs, and by models of profit-sharing". Here, despite the outward appearance of authentic and ethical care, we find that care is being redefined - care comes to be normalized, disciplined, technologized. The self, while it appears to be relating ethically, instead relies on the expert terms and "best practices" that are defined by the industry.

Care of the self, in its ethical meaning, is instead a practice of autonomous self-government and freedom; a repertory of practices through which the self recreates itself each day. It is not exercised in a solipsistic manner, since it is a relational practice implying care for others as well as for the self. It is a set of practices that stimulates critical questioning and thinking, and is skeptical of the idea that there can be ahistorical and necessary boundaries and constraints that cannot be criticized. While care ethics emphasizes care for others over care of the self, it is nevertheless also true that the moral qualities (attention, responsibility and reactivity) that Joan Tronto [8] regards as essential to care may be considered as implicitly linked to practices and exercises in relation to the self. Care ethics involves a self that refuses to find ready-made answers and principles to moral dilemmas and operates instead with a contextual morality open to the contingency of the encounter with the concrete other and the concrete care situation, through maintaining an openended inner dialogue of the self with oneself and reinventing oneself each time in relation to the other (be it oneself, other human beings, non-human animals, the environment or the world) [31].

With $99 \%$ of the world's population finding itself in precarious existential conditions, and often also in precarious economic and work conditions, this places individuals, and especially those whose work implies caring for others - such as academics and social workers -, near to personal crises that gives to the very word precarity a critical-transformative potential [32]. It is in trying to respond to this situation of crisis, in trying to care for oneself not only with the aim of surviving in a solipsistic manner but of living a complete life with others in conditions of contingency, that one finds critical resources in sentiments and attitudes, such as skepticism and cynicism, to challenge neoliberal discourses. Within this neoliberal climate, despite bad feelings concerning oneself including depression being so widespread and seemingly intrinsic to neoliberalism itself, it is possible to distance oneself from their medical interpretation, to "depathologize" them as suggested by Ann Cvetkovich [30], and view them as public feelings and as critical resources linked to political practices meant to change oneself, to operate on the self with the aim of transforming it. Thus, care of the self, as Foucault emphasizes in his late writings, presupposes a certain form of criticism aimed at enlarging our spaces of freedom. For care ethics, it is fundamental to examine the conditions that favor the emergence of this form of care of the self, in both its critique of neoliberal precarity and its endorsement of a caring democracy.

\section{Acknowledgment}

I would like to thank Editage (www.editage.com) for English language editing.

\section{References}

1. Lemke S (2016) Inequality, poverty, and precarity in 
contemporary american culture. Palgrave Macmillan, New York.

2. Kalleberg A (2018) Precarious lives: Job insecurity and well-being in rich democracies. Polity Press, London.

3. Berlant L (2011) Cruel optimism. Duke University Press, Durham.

4. LaVaque-Manty M (2009) Findings theoretical concepts in the real world: The case of the precariat. In: Boudewijn de Bruin, Christoher F Zurn, New waves in political philosophy. Palgrave MacMillan, London, 105-124.

5. Butler J (2015) Foreword. In: Lorey I, State of insecurity: Government of the precarious. Verso, New York.

6. Foucault M (2008) The birth of biopolitics: Lectures at the college de france, 1978-1979. Palgrave MacMillan, London.

7. Dardot P, Laval C (2014) The new way of the world: On neoliberal society. Verso, London.

8. Tronto J (1993) Moral boundaries. A Political argument for an ethic of care. Routledge, New York.

9. Tronto J (2015) Caring democracy: Markets, equality, and justice. New York University Press, New York.

10. Puig de la Bellacasa M (2017) Matters of care: Speculative ethics in more than human worlds. University of Minnesota Press, London.

11. Murray SJ (2007) Care and the self: Biotechnology, reproduction, and the good life. Philos Ethics Humanit Med.

12. Byung-Chul H (2015) The Burnout Society. Stanford university press, Redwood City, California.

13. Gill R (2009) Breaking the silence: The hidden injuries of neoliberal academia. In: Secrecy and silence in the research process: Feminist reflections, $R$ Ryan-Flood and R Gill. Routledge, London, 228-244.

14. MacLean K (2016) Sanity, "madness," and the academy. Wiley Online Library 60: 181-191.

15. Jones C (2001) Voices from the front-line: State social workers and new labour. British Journal of Social Work 31: 547-562.

16. Dustin D (2007) The mcdonaldization of social work. Aldersho, Ashgate.

17. Carey M (2014) Mind the gaps: Understanding the rise and implications of different types of cynicism within statutory social work. The British Journal of Social Work 44: 127-144.

18. Lorenz C (2012) If you're so smart, why are you under surveillance? universities, neoliberalism, and new public management. Critical Inquiry 38: 599-629.

19. Sorrentino V (2012) Biopolitica, liberta e cura: Saggio su foucault. Aracne, Roma.

20. Foucault M (2007) Security, territory, population: Lectures at the college de france 1977-1978. Palgrave MacMillan, London.

21. Cooper M (2017) Family values: Between neoliberalism and the new social conservatism. Zone Books, Brooklin, New York.

22. Laval C (2018) Foucault, bourdieu et la question neoliberale. La Decouverte, Paris.

23. Feher M (2008) Self-appreciation; or, the aspirations of human capital. Public Culture 21: 21-41.

24. Crary J (2014) Late capitalism and the ends of sleep. Verso, London.

25. Braime $H$ (2013) From coping to thriving: How to turn selfcare into a way of life. Individuate Press.

26. Reading $S$ (2017) The self-care revolution: Smart habits \& simple practices to allow you to flourish. Aster.

27. Dean JW, Brandes P, Dharwadkar R (1998) Organizational cynicism. Academy of Management Review 23: 341-352.

28. Flachbartova $L$ (2017) The Care of the self and diogene's ascetic practices. In: Suvak V, Care of the Self: Ancient problematizations of life and contemporary thought. Brill Rodopi, Leiden, Boston.

29. Berg M, Seeber BK (2016) The Slow professor toronto: Challenging the culture of speed in the academy. University Press, Toronto.

30. Cvetkovich A (2012) Depression: A public feeling. Duke University Press, Durham.

31. Mozere L (2004) Le «souci de soi» chez foucault et le souci dans une ethique politique du care. Quelques pistes de travail. Le Portique. Revue de philosophie et de sciences humaines 13-14.

32. Millar KM (2017) Toward a critical politics of precarity. Sociology Compass 11: 1-11.

DOI: $10.36959 / 763 / 496$

Copyright: (C) 2019 Casalini B. This is an open-access article distributed under the terms of the Creative Commons Attribution License, which permits unrestricted use, distribution, and reproduction in any medium, provided the original author and source are credited. 